Editorial

\title{
Preface: Remote Sensing in Flood Monitoring and Management
}

\author{
Guy J-P. Schumann ${ }^{+}$ \\ Received: 14 December 2015; Accepted: 15 December 2015; Published: 16 December 2015 \\ Academic Editor: Prasad S. Thenkabail \\ Joint Institute for Regional Earth System Science and Engineering, University of California Los Angeles, \\ Los Angeles, CA 90095, USA; gjpschumann@gmail.com; Tel.: +1-626-394-3538 \\ + Now at Remote Sensing Solutions Inc., Monrovia, CA 91016, USA
}

\begin{abstract}
This Special Issue is a collection of papers studying the use of remote sensing data and methods for flood monitoring and management. The articles contributed span a wide range of topics and present novel processing techniques, review methods and discuss limitations, and also report on current capabilities and outline emerging needs. This preface provides a brief overview of the content.
\end{abstract}

Keywords: flood hazard and risk; satellite imagery; altimetry; digital elevation model; hydrodynamics

\section{Scope}

Floods can be mapped and monitored with remotely sensed data acquired by aircraft and satellites, or even from ground-based platforms. The sensors and data processing techniques that exist to derive information about floods are numerous. Instruments that record flood events may operate in the visible, thermal and microwave range of the electromagnetic spectrum. Due to the limitations posed by adverse weather conditions during flood events, active radar is invaluable for monitoring floods; however, if a visible image of flooding can be acquired, retrieving useful information from this is often more straightforward.

Apart from providing direct information about flooding, remote sensing data can also be integrated with flood models (via model calibration or validation, and data assimilation techniques) or provide floodplain topography data to augment the amount and type of information available for efficient flood management. There have been notable studies on integrating remotely sensed data with flood modeling since the late 1990s and there is now a general consensus among space agencies to strengthen the support that satellite missions can offer. This trend has stimulated more research in this area, and significant progress has been achieved in recent years in fostering our understanding of the ways in which remote sensing can support flood monitoring and management.

This Special Issue presents a collection of work on current efforts to aid advancing flood monitoring and management through remotely sensed data. The following section gives a brief overview of the large variety of papers contributed to this Special Issue, presenting the use of remote sensing data and methods in flood research and applications.

\section{Overview of Contributions}

The variety of high quality research and application studies published in this Special Issue is large and I only provide a brief overview here. I encourage the reader to refer to the entire Special Issue to gain insight into the current state-of-the-art methods employed in remote sensing for flood monitoring and management.

The contributed articles cover local to global scale applications and range across a number of fields (e.g., disaster management and societal impact, flood forecasting, rainfall-runoff modeling, 
DEM processing, water quality, and wetlands). For instance, Schroeder et al. [1] developed a global, multi-year fractional surface water index from satellite microwave data. Revilla-Romero et al. [2] show the use of a similar index to complement global flood forecasting, and the potential of combining multi-annual satellite flood maps and modeling to provide better flood hazard mapping capabilities is demonstrated by Giustarini et al. [3]. At more regional to local scales, imagery can be used to detect localized flooding [4], assist rapid response [5], infer flood damages [6] and exposure [7], and even map temporal change [8,9], inundation dynamics [10] as well as flood regimes [11].

A number of papers in this Special Issue also demonstrate that much is to be gained from combining satellite flood maps with digital elevation models (DEMs) and also distributed process models. Merging zonal flood information with topography can reveal complexities in water surface dynamics [12,13] and in local flow connectivity [14], which are difficult to observe with flood imagery or maps alone. Integrating satellite data with models can lead to significant improvements in the latter, especially for large scale flood hydrology and hydrodynamics, as illustrated by Pinel et al. [15] in the Amazon Basin and by Jung and Jasinski [16] in the Atchafalaya Basin. Data assimilation of remotely sensed data can be employed to help improve simulations from different types of models, as illustrated by Reager et al. [17] for a land surface model and GRACE terrestrial water storage and by Massari et al. [18] for satellite soil moisture and a rainfall-runoff model.

With a proliferation of free Earth Observation data now and in the near future, there is an obvious need to not only understand the limitations and errors of the data and methods, as examined for flood mapping by Ticehurst et al. [19] and for river plume monitoring by Devlin et al. [20], but also to develop more sophisticated data processing algorithms (e.g., [21]) as well as robust frameworks for handling the many heterogeneous geospatial data sets [22] and for effective information management and transfer across networks [23].

Acknowledgments: It has been a great pleasure leading this Special Issue. I would like to thank the journal for giving me this opportunity but above all I would like to thank all the authors for contributing their work.

Conflicts of Interest: The author declares no conflict of interest.

\section{References}

1. Schroeder, R.; McDonald, K.C.; Chapman, B.D.; Jensen, K.; Podest, E.; Tessler, Z.D.; Bohn, T.J.; Zimmermann, R. Development and Evaluation of a Multi-Year Fractional Surface Water Data Set Derived from Active/Passive Microwave Remote Sensing Data. Remote Sens. 2015, 7, doi:10.3390/rs71215843.

2. Revilla-Romero, B.; Hirpa, F.A.; Pozo, J.T.D.; Salamon, P.; Brakenridge, R.; Pappenberger, F.; de Groeve, T. On the Use of Global Flood Forecasts and Satellite-Derived Inundation Maps for Flood Monitoring in Data-Sparse Regions. Remote Sens. 2015, 7, doi:10.3390/rs71115702.

3. Giustarini, L.; Chini, M.; Hostache, R.; Pappenberger, F.; Matgen, P. Flood Hazard Mapping Combining Hydrodynamic Modeling and Multi Annual Remote Sensing data. Remote Sens. 2015, 7, doi:10.3390/ rs71014200.

4. Malinowski, R.; Groom, G.; Schwanghart, W.; Heckrath, G. Detection and Delineation of Localized Flooding from WorldView-2 Multispectral Data. Remote Sens. 2015, 7, doi:10.3390/rs71114853.

5. Chung, H.W.; Liu, C.C.; Cheng, I.F.; Lee, Y.R.; Shieh, M.C. Rapid Response to a Typhoon-Induced Flood with an SAR-Derived Map of Inundated Areas: Case Study and Validation. Remote Sens. 2015, 7, doi:10.3390/rs70911954.

6. Kwak, Y.; Arifuzzanman, B.; Iwami, Y. Prompt Proxy Mapping of Flood Damaged Rice Fields Using MODIS-Derived Indices. Remote Sens. 2015, 7, doi:10.3390/rs71215805.

7. Gómez, A.J.S.; di Baldassarre, G.; Rodhe, A.; Pohjola, V.A. Remotely Sensed Nightlights to Map Societal Exposure to Hydrometeorological Hazards. Remote Sens. 2015, 7, doi:10.3390/rs70912380.

8. Byun, Y.; Han, Y.; Chae, T. Image Fusion-Based Change Detection for Flood Extent Extraction Using Bi-Temporal Very High-Resolution Satellite Images. Remote Sens. 2015, 7, doi:10.3390/rs70810347.

9. Yuan, T.; Lee, H.; Jung, H.C. Toward Estimating Wetland Water Level Changes Based on Hydrological Sensitivity Analysis of PALSAR Backscattering Coefficients over Different Vegetation Fields. Remote Sens. 2015, 7, doi:10.3390/rs70303153. 
10. Martinis, S.; Rieke, C. Backscatter Analysis Using Multi-Temporal and Multi-Frequency SAR Data in the Context of Flood Mapping at River Saale, Germany. Remote Sens. 2015, 7, doi:10.3390/rs70607732.

11. Hu, Y.; Huang, J.; Du, Y.; Han, P.; Huang, W. Monitoring Spatial and Temporal Dynamics of Flood Regimes and Their Relation to Wetland Landscape Patterns in Dongting Lake from MODIS Time-Series Imagery. Remote Sens. 2015, 7, doi:10.3390/rs70607494.

12. Wu, G.; Liu, Y. Combining Multispectral Imagery with in situ Topographic Data Reveals Complex Water Level Variation in China's Largest Freshwater Lake. Remote Sens. 2015, 7, doi:10.3390/rs71013466.

13. Zhang, P.; Lu, J.; Feng, L.; Chen, X.; Zhang, L.; Xiao, X.; Liu, H. Hydrodynamic and Inundation Modeling of China's Largest Freshwater Lake Aided by Remote Sensing Data. Remote Sens. 2015, 7, doi:10.3390/rs70404858.

14. Poppenga, S.; Worstell, B. Evaluation of Airborne Lidar Elevation Surfaces for Propagation of Coastal Inundation: The Importance of Hydrologic Connectivity. Remote Sens. 2015, 7, doi:10.3390/rs70911695.

15. Pinel, S.; Bonnet, M.P.; Santos da Silva, J.; Moreira, D.; Calmant, S.; Satgé, F.; Seyler, F. Correction of Interferometric and Vegetation Biases in the SRTMGL1 Spaceborne DEM with Hydrological Conditioning towards Improved Hydrodynamics Modeling in the Amazon Basin. Remote Sens. 2015, 7, doi:10.3390/ rs71215822.

16. Jung, H.C.; Jasinski, M.F. Sensitivity of a Floodplain Hydrodynamic Model to Satellite-Based DEM Scale and Accuracy: Case Study—The Atchafalaya Basin. Remote Sens. 2015, 7, doi:10.3390/rs70607938.

17. Reager, J.T.; Thomas, A.C.; Sproles, E.A.; Rodell, M.; Beaudoing, H.K.; Li, B.; Famiglietti, J.S. Assimilation of GRACE Terrestrial Water Storage Observations into a Land Surface Model for the Assessment of Regional Flood Potential. Remote Sens. 2015, 7, doi:10.3390/rs71114663.

18. Massari, C.; Brocca, L.; Tarpanelli, A.; Moramarco, T. Data Assimilation of Satellite Soil Moisture into Rainfall-Runoff Modelling: A Complex Recipe? Remote Sens. 2015, 7, doi:10.3390/rs70911403.

19. Ticehurst, C.; Guerschman, J.P.; Chen, Y. The Strengths and Limitations in Using the Daily MODIS Open Water Likelihood Algorithm for Identifying Flood Events. Remote Sens. 2014, 6, doi:10.3390/rs61211791.

20. Devlin, M.J.; Petus, C.; da Silva, E.; Tracey, D.; Wolff, N.H.; Waterhouse, J.; Brodie, J. Water Quality and River Plume Monitoring in the Great Barrier Reef: An Overview of Methods Based on Ocean Colour Satellite Data. Remote Sens. 2015, 7, doi:10.3390/rs71012909.

21. Feng, Q.; Gong, J.; Liu, J.; Li, Y. Flood Mapping Based on Multiple Endmember Spectral Mixture Analysis and Random Forest Classifier? The Case of Yuyao, China. Remote Sens. 2015, 7, doi:10.3390/rs70912539.

22. Chen, N.; Zhou, L.; Chen, Z. A Sharable and Efficient Metadata Model for Heterogeneous Earth Observation Data Retrieval in Multi-Scale Flood Mapping. Remote Sens. 2015, 7, doi:10.3390/rs70809610.

23. Chen, N.; Du, W.; Song, F.; Chen, Z. FLCNDEMF: An Event Metamodel for Flood Process Information Management under the Sensor Web Environment. Remote Sens. 2015, 7, doi:10.3390/rs70607231.

(C) 2015 by the author; licensee MDPI, Basel, Switzerland. This article is an open access article distributed under the terms and conditions of the Creative Commons by Attribution (CC-BY) license (http:/ / creativecommons.org/licenses/by/4.0/). 